\title{
Consumer attitudes, knowledge, and behavior related to salt consumption in sentinel countries of the Americas
}

\author{
Rafael Moreira Claro, ${ }^{1}$ Hubert Linders, ${ }^{2}$ Camila Zancheta Ricardo, ${ }^{3}$ \\ Branka Legetic, ${ }^{4}$ and Norm R. C. Campbel/ ${ }^{5}$
}

Suggested citation Claro RM, Linders H, Ricardo CZ, Legetic B, Campbell NRC. Consumer attitudes, knowledge, and behavior related to salt consumption in sentinel countries of the Americas. Rev Panam Salud Publica. 2012;32(4):265-73.

ABSTRACT Objective. To describe individual attitudes, knowledge, and behavior regarding salt intake, its dietary sources, and current food-labeling practices related to salt and sodium in five sentinel countries of the Americas.

Methods. A convenience sample of 1992 adults ( $\geq 18$ years old) from Argentina, Canada, Chile, Costa Rica, and Ecuador (approximately 400 from each country) was obtained between September 2010 and February 2011. Data collection was conducted in shopping malls or major commercial areas using a questionnaire containing 33 questions. Descriptive estimates are presented for the total sample and stratified by country and sociodemographic characteristics of the studied population.

Results. Almost $90 \%$ of participants associated excess intake of salt with the occurrence of adverse health conditions, more than $60 \%$ indicated they were trying to reduce their current intake of salt, and more than $30 \%$ believed reducing dietary salt to be of high importance. Only $26 \%$ of participants claimed to know the existence of a recommended maximum value of salt or sodium intake and $47 \%$ of them stated they knew the content of salt in food items. More than $80 \%$ of participants said that they would like food labeling to indicate high, medium, and low levels of salt or sodium and would like to see a clear warning label on packages of foods high in salt.

Conclusions. Additional effort is required to increase consumers' knowledge about the existence of a maximum limit for intake and to improve their capacity to accurately monitor and reduce their personal salt consumption.

Key words Sodium; attitude; knowledge; behavior; consumer organizations; Americas.

Excessive salt intake is a major public health concern (1). It causes hyperten-

\footnotetext{
${ }^{1}$ Universidade de São Paulo-Nutrição, São Paulo, Brazil. Send correspondence to: Rafael Claro, rclaro@usp.br

2 Consumers International, Santiago, Chile.

${ }^{3}$ Núcleo de Pesquisas Epidemiológicas em Nutrição

e Saúde, Universidade de São Paulo, São Paulo, Brazil.

${ }^{4}$ Pan American Health Organization, Washington, D.C., United States of America.

${ }^{5}$ Department of Medicine, University of Calgary, Calgary, Alberta, Canada.
}

sion (2), and epidemiologic and pathophysiologic evidence associates excessive intake of salt with several adverse health conditions such as stroke and coronary heart disease (2), kidney stones (3), gastric cancer (4), osteoporosis (5), and, indirectly, even with obesity (6). Cardiovascular diseases are a major cause of mortality worldwide and increased blood pressure is the most important risk factor for cardiovascular disease (7). Estimates indicate that increased blood pressure is responsible for approximately half of the global cardiovascular disease burden (7).

The World Health Organization (WHO) recommends a maximum level of salt intake per person of $<5 \mathrm{~g} /$ day (1). Although reliable, national representative information on salt consumption remains scarce; available data indicate that most populations worldwide have an av- 
erage salt intake per person $>6 \mathrm{~g} /$ day; in many Eastern European and Asian countries, it is even higher than $12 \mathrm{~g} /$ day (8). Specifically, in the Americas, excessive levels of salt intake are found in recent estimates from Argentina (12 g/day) (9), Brazil (11 g/day) (10), Canada (8 g/day) (11), Chile (9 g/day) (12), and the United States of America (8.7 g/day) (13).

Efforts to reduce dietary salt are recommended by WHO to be based on: 1) monitoring and evaluating how much salt is being consumed; identifying dietary sources of salt; determining consumer attitudes, knowledge, and behavior toward dietary salt as a health risk; 2) reducing the amount of salt added to food; and 3) introducing programs to increase consumer knowledge and health behavior to reduce dietary salt consumption (WHO United Kingdom) $(13,14)$. In September 2009, the Pan American Health Organization (PAHO) established an expert group to examine excessive dietary salt as a health risk in the Americas, issue evidence-based policy recommendations for salt reduction in the region, and develop tools and resources to aid the region to reduce dietary salt intake $(15,16)$. This expert group has set a goal for the region to obtain a gradual and sustained reduction in salt intake to reach an average level per person of $<5 \mathrm{~g}$ /day by 2020 (12).

The primary aim of this research is to describe individuals' attitudes, knowledge, and behavior regarding salt intake; dietary sources of salt; and current foodlabeling practices related to salt and sodium in five sentinel PAHO countries.

\section{METHODS}

\section{Study design and sampling strategy}

This research is a transversal study. Participants were 18 years or older, coming from Argentina (Cañada de Gómez, Villa Gobernador Gálvez, and Rosario), Canada (Calgary), Chile (Santiago), Costa Rica (San José), and Ecuador (Quito). In Argentina, Chile, Costa Rica, and Ecuador consumer organizations were invited to conduct the survey locally. These organizations were, respectively, Unión de Usuarios y Consumidores, Filial Rosario; Conadecus; Fundación Bandera Ecológica; and Tribuna. In Canada, N.R.C.C. at the University of Calgary oversaw implementation of the survey. Each organization was equipped with the study protocol, containing clear and objective instructions about the procedures to be adopted in relation to the sampling strategy, data collection, and initial organization of the information.

The survey was executed between September 2010 and February 2011. At each study site, the organization conducting the survey was oriented to first verify the effectiveness of the questionnaire, provided in Spanish except in Canada where it was done in English. Next, each organization selected shopping malls or major commercial areas (e.g., the intersection of two shopping streets) to position its researchers for data collection (with a minimum of 2 and a maximum of 15 at each site).

A minimum of 400 participants were to be sequentially approached in each study site, making it possible to estimate the frequency of any answer in the questionnaire with a confidence level of $95 \%$ and a maximum error of about 5 percentage points (17). Data collection was conducted during business hours on weekdays and was to continue up to the completion of the minimum number of interviews required. The interviewers approached passing consumers and invited them to take part in a study using a questionnaire about attitudes, knowledge, and behavior related to salt and sodium consumption in five countries of the Americas; they stated that the study was conducted in partnership between the local organization, Consumers International, and PAHO. The interviewer stated that, by answering the questionnaire the participant expressed implied consent to participate. If a potential participant declined to participate, the researcher would repeat the process by approaching the next person. After obtaining consumers' consent, the researcher was instructed to read and fill out the questionnaire according to the responses, always respecting the order of questions. Local sites were allowed to use printed forms or to record the answers directly on a laptop. Results from participants who failed to provide a response to the demographic section of the questionnaire or to more than $75 \%$ of questions were excluded from the analysis.

\section{Survey instrument}

A questionnaire containing 33 questions was designed to address knowledge (e.g., difference between salt and sodium), attitudes, and behavior related to salt intake; intention and actions taken to reduce salt intake; the presence of chronic diseases (e.g., high blood pressure, heart failure); labeling preferences; and participants' demographics. For consistency throughout the questionnaire the term "salt" or "salt/sodium" was used on all questions.

The first block (four questions) addressed participants' demographic characteristics (gender, age, level of education, and presence of children under age 16 living in the household). The second block (seven questions) assessed participants' attitude statements related to salt intake and health.

In the third block (10 multiple choice questions and 4 open-answer questions), participants were asked to identify: the frequency with which they added salt to foods during cooking and at the table, their personal belief about their current salt intake, health conditions related to high salt intake, the importance of reducing dietary salt and sodium consumption and actions taken to achieve this goal, knowledge about the existence of a maximum limit for salt intake, the difference between salt and sodium, and the use of food labels to guide choices. A set of five questions was used to assess participants' preferences related to how the salt and sodium content of packed foods is displayed on labels.

The questionnaire was developed by a subgroup of the PAHO expert group, revised in consultations with experts within the PAHO expert group, and field-tested in focus groups of participants in Latin America and Canada (Appendix 1). Questions were developed based on the experience and expertise of the expert group members and on questions used in previous surveys (18-20).

\section{Data analysis}

Data collected at each study site were grouped. Quality and consistency of data were verified for each country individually and for the entire data set. This paper presents descriptive estimates of the main topics the survey explored. The frequency (and corresponding 95\% confidence interval) of each topic was described for the total sample and stratified by country. Additionally, the importance conceived by the participant to reduce his or her salt intake and the percentage of participants claiming to know the existence of a recommended maximum value 
for salt intake was also explored according to gender, age group, and education.

All data obtained from the questionnaires were organized by using the software Stata for Windows version 10.1.

The study protocol was approved by the Ethics Committee of the University of Calgary in Canada. Data collection in Argentina, Chile, Costa Rica, and Ecuador was done by Consumer international field staff and does not include ethical approval.

\section{RESULTS}

\section{Sample characteristics}

A sample of 2000 participants was initially obtained. From this sample, four individuals in Costa Rica and three in Ecuador failed to provide valid information on age (18 years or older), while one individual in Ecuador failed to answer more than $75 \%$ of the questionnaire and thus were excluded from the analysis. A total of 1992 individuals provided a valid response to the entire questionnaire and were included in the study. Slightly more than half were female $(55 \%)$ and almost one-half were between 18 and 34 years old. Approximately $85 \%$ had at least completed high school and $34 \%$ declared the presence of children under age 16 living at home (Table 1).

\section{Attitudes, knowledge, and behavior}

Approximately $70 \%$ of participants stated they generally were in good health (ranging from 56\% in Chile to
$85 \%$ in Canada), whereas $80 \%$ mentioned trying to eat a healthy diet. On the other hand, $45 \%$ of participants stated they felt too much pressure to eat a healthy diet. Almost $90 \%$ agreed that eating a diet high in salt can cause serious health issues (ranging from $76 \%$ in Ecuador to $98 \%$ in Argentina) but only $13 \%$ of participants believed they personally consumed too much salt. The number of respondents indicating they ate too much salt reached its minimum in Ecuador $(4 \%)$ and its maximum in Canada (26\%). Approximately $73 \%$ of participants indicated they tried to reduce their consumption of fat, while a smaller percentage of participants $(61 \%)$ aimed to reduce their salt intake. The proportion of participants aiming to reduce salt intake was associated with the capacity to recognize high sodium intake as a health threat $\left(\mathrm{chi}^{2}\right.$ test, $P<$ 0.05). Almost one-half of participants indicated they knew the amount of salt food contains (ranging from $34 \%$ in Ecuador to $62 \%$ in Chile) and 50\% also indicated that the amount of information available on food labels was sufficient. The percentage of respondents satisfied with the amount of information present on food labels reached its minimum in Canada (34\%) and its maximum in Ecuador $(72 \%)$ (Table 2).

More than $30 \%$ of participants believed that limiting their intake of salt was very important (Table 3) while $44 \%$ believed it was somewhat important (data not shown). This characteristic was also associated with the capacity to recognize high sodium intake as a health threat (chi ${ }^{2}$ test, $\left.P<0.05\right)$. This awareness was greater in women $(40 \%)$ than in men $(26 \%)$ and tended to increase with age, ranging from $24 \%$ for the population aged 18-24 years to $68 \%$ for the population aged 65 years or older. There was a tendency for higher percentages of people to give high importance to salt reduction in the high and the low education categories. The number of participants giving high importance to reducing their salt intake reached its minimum in Ecuador $(23 \%)$ and its maximum in Argentina (43\%).

Only $26 \%$ of participants reported knowing the existence of a recommended maximum value of salt intake (Table 4) and only $7 \%$ of participants were able to correctly identify the value (data not shown). The percentage was greater in females than in males $(29 \%$ and $22 \%$, respectively) and tended to increase with education, ranging from $15 \%$ to $35 \%$ in the lowest to highest education categories. No relationship with aging was found. Knowledge of the existence of a maximum recommended value for salt intake reached its minimum in Argentina $(6 \%)$ and its maximum in Canada (54\%).

\section{Labeling}

Only about $35 \%$ of the people interviewed stated that they read nutrition labels on food packages always or often, ranging from $24 \%$ in Costa Rica to $58 \%$ in Canada (Table 5). On the other hand, a slightly higher percentage (40\%) men-

TABLE 1. Demographic characteristics of participants $(n=1992)$ in five sentinel countries of the Americas, ${ }^{\text {a }} 2010$

\begin{tabular}{|c|c|c|c|c|c|c|c|c|c|c|c|c|}
\hline \multirow[b]{2}{*}{ Variable } & \multicolumn{2}{|c|}{ Total participants } & \multicolumn{2}{|c|}{ Argentina $($ No. $=400)$} & \multicolumn{2}{|c|}{ Canada (No. = 399) } & \multicolumn{2}{|c|}{ Chile (No. $=400)$} & \multicolumn{2}{|c|}{ Costa Rica (No. = 396) } & \multicolumn{2}{|c|}{ Ecuador $($ No. $=397)$} \\
\hline & $\%$ & $95 \% \mathrm{Cl}$ & $\%$ & $95 \% \mathrm{Cl}$ & $\%$ & $95 \% \mathrm{Cl}$ & $\%$ & $95 \% \mathrm{Cl}$ & $\%$ & $95 \% \mathrm{Cl}$ & $\%$ & $95 \% \mathrm{Cl}$ \\
\hline \multicolumn{13}{|l|}{ Gender } \\
\hline Male & 44.1 & $41.9-46.3$ & 41.8 & $36.9-46.6$ & 39.1 & $34.3-43.9$ & 48.5 & $43.6-53.4$ & 48.5 & $43.6-53.4$ & 42.6 & $37.7-47.4$ \\
\hline Female & 55.9 & $53.7-58.1$ & 58.3 & $53.4-63.1$ & 60.9 & $56.1-65.7$ & 51.5 & $46.6-56.4$ & 51.5 & $46.6-56.4$ & 57.4 & $52.6-62.3$ \\
\hline \multicolumn{13}{|l|}{ Age group (years) } \\
\hline $18-24$ & 21.4 & $19.6-23.2$ & 11.3 & $8.1-14.4$ & 36.8 & $32.1-41.6$ & 19.8 & $15.8-23.7$ & 31.8 & $27.2-36.4$ & 7.3 & $4.7-9.9$ \\
\hline $25-34$ & 27.3 & $25.4-29.3$ & 26.0 & $21.7-30.3$ & 23.8 & $19.6-28.0$ & 30.8 & $26.2-35.3$ & 32.3 & $27.7-36.9$ & 23.7 & $19.5-27.9$ \\
\hline $35-44$ & 18.7 & $17.0-20.4$ & 17.8 & $14.0-21.5$ & 11.5 & $8.4-14.7$ & 26.0 & $21.7-30.3$ & 15.4 & $11.8-19.0$ & 22.9 & $18.8-27.1$ \\
\hline $45-54$ & 16.1 & $14.5-17.7$ & 16.3 & $12.6-19.9$ & 10.3 & 7.3-13.3 & 17.5 & $13.8-21.2$ & 10.4 & $7.3-13.4$ & 25.9 & $21.6-30.3$ \\
\hline $55-64$ & 9.7 & $8.4-11.0$ & 13.5 & $10.1-16.9$ & 6.5 & $4.1-8.9$ & 4.8 & $2.7-6.8$ & 7.3 & $4.8-9.9$ & 16.6 & $13.0-20.3$ \\
\hline$\geq 65$ & 6.8 & $5.7-7.9$ & 15.3 & $11.7-18.8$ & 11.0 & $7.9-14.1$ & 1.3 & $0.2-2.3$ & 2.8 & $1.2-4.4$ & 3.5 & $1.7-5.3$ \\
\hline \multicolumn{13}{|l|}{ Education } \\
\hline None and primary & 15.2 & $13.6-16.8$ & 35.0 & $30.3-39.7$ & 11.3 & $8.2-14.4$ & 7.3 & $4.7-9.8$ & 9.6 & $6.7-12.5$ & 12.8 & $9.5-16.1$ \\
\hline Secondary & 46.0 & $43.8-48.2$ & 41.0 & $36.2-45.8$ & 40.4 & $35.5-45.2$ & 55.0 & $50.1-59.9$ & 47.2 & $42.3-52.1$ & 46.3 & $41.4-51.3$ \\
\hline Higher & 38.8 & $36.7-40.9$ & 24.0 & $19.8-28.2$ & 48.4 & $43.5-53.3$ & 37.8 & $33.0-42.5$ & 43.2 & $38.3-48.1$ & 40.8 & $36.0-45.6$ \\
\hline \multicolumn{13}{|l|}{ Children under } \\
\hline age 16 at home & 34.3 & $32.2-36.4$ & 43.8 & $38.9-48.6$ & 20.3 & $16.3-24.3$ & 31.3 & $26.7-35.8$ & 35.9 & $31.1-40.6$ & 40.3 & $35.5-45.1$ \\
\hline
\end{tabular}

Note: Cl: confidence interval.

a Argentina (Cañada de Gómez, Villa Gobernador Gálvez, and Rosario), Canada (Calgary), Chile (Santiago), Costa Rica (San José), and Ecuador (Quito). 
TABLE 2. Summary of answers to survey (Appendix 1) of self-reported attitudes, knowledge, and behavior related to health, diet, and salt consumption $(n=1992)$ in five sentinel countries of the Americas, ${ }^{\text {a }} 2010$

\begin{tabular}{|c|c|c|c|c|c|c|}
\hline \multirow[b]{2}{*}{ Statement } & \multicolumn{6}{|c|}{ Percent agreeing with statement } \\
\hline & Total & Argentina & Canada & Chile & Costa Rica & Ecuador \\
\hline My health is generally good. & 72.4 & 79.8 & 84.7 & 55.8 & 67.9 & 74.1 \\
\hline I try to eat a healthy diet. & 80.3 & 84.3 & 90.0 & 76.3 & 71.0 & 80.1 \\
\hline $\begin{array}{l}\text { There is too much pressure to } \\
\text { eat healthily these days. }\end{array}$ & 45.1 & 40.8 & 58.4 & 54.0 & 28.5 & 43.8 \\
\hline $\begin{array}{l}\text { I believe that eating a diet high in } \\
\text { salt can cause serious health }\end{array}$ & & & & & & \\
\hline $\begin{array}{l}\text { problems. } \\
\text { I think I consume too much salt. }\end{array}$ & $\begin{array}{l}88.5 \\
12.9\end{array}$ & $\begin{array}{l}97.5 \\
12.5\end{array}$ & $\begin{array}{l}93.2 \\
26.1\end{array}$ & $\begin{array}{l}89.0 \\
11.5\end{array}$ & $\begin{array}{l}86.9 \\
10.1\end{array}$ & $\begin{array}{r}75.6 \\
4.3\end{array}$ \\
\hline $\begin{array}{l}\text { I try to minimize the amount of } \\
\text { fat I eat. } \\
\text { I try to minimize the amount of salt }\end{array}$ & 72.6 & 78.8 & 79.7 & 70.5 & 63.4 & 70.8 \\
\hline $\begin{array}{l}\text { I consume. } \\
\text { I don't know the difference between }\end{array}$ & 60.7 & 70.8 & 66.7 & 65.5 & 54.0 & 46.3 \\
\hline $\begin{array}{l}\text { salt and sodium. } \\
\text { I know in general how much salt }\end{array}$ & 75.6 & 89,0 & 73,1 & 82,0 & 63,9 & 70,0 \\
\hline $\begin{array}{l}\text { food contains. } \\
\text { I think there is sufficient nutritional } \\
\text { information on labels of food } \\
\text { and drinks. }\end{array}$ & 47.6 & 39.8 & 51.6 & 62.0 & 50.5 & 34.0 \\
\hline
\end{tabular}

TABLE 3. Percentage of participants who conceive high importance of reducing their salt and sodium intake according to gender, age group, and education $(n=1992)$ in five sentinel countries of the Americas, ${ }^{\mathrm{a}} 2010$

\begin{tabular}{|c|c|c|c|c|c|c|}
\hline \multirow[b]{2}{*}{ Variable } & \multicolumn{6}{|c|}{ Percent of participants } \\
\hline & Total & Argentina & Canada & Chile & Costa Rica & Ecuador \\
\hline \multicolumn{7}{|l|}{ Gender } \\
\hline Male & 25.6 & 34.3 & 28.4 & 22.8 & 25.8 & 17.4 \\
\hline Female & 40.0 & 49.4 & 36.3 & 47.8 & 39.6 & 27.1 \\
\hline \multicolumn{7}{|l|}{ Age group (years) } \\
\hline $18-24$ & 23.6 & 13.3 & 22.1 & 32.9 & 20.8 & 34.6 \\
\hline $25-34$ & 29.7 & 35.6 & 27.4 & 34.7 & 30.7 & 17.4 \\
\hline $35-44$ & 30.2 & 32.4 & 28.3 & 34.6 & 44.3 & 14.1 \\
\hline $45-54$ & 34.6 & 32.8 & 51.2 & 32.9 & 37.5 & 29.1 \\
\hline $55-64$ & 47.9 & 63.5 & 46.2 & 63.2 & 65.5 & 24.2 \\
\hline$\geq 65$ & 67.9 & 83.6 & 64.3 & 60.0 & 30.0 & 38.5 \\
\hline \multicolumn{7}{|l|}{ Education } \\
\hline None and primary & 41.1 & 55.7 & 22.2 & 37.9 & 31.6 & 24.4 \\
\hline Secondary & 28.9 & 31.7 & 34.6 & 32.9 & 28.6 & 16.8 \\
\hline Higher & 36.2 & 43.8 & 34.6 & 39.3 & 37.9 & 29.2 \\
\hline Total & 33.6 & 43.1 & 33.2 & 35.7 & 32.9 & 22.9 \\
\hline
\end{tabular}

Source: question 6 from Appendix 1: Survey on knowledge, attitude and behavior toward dietary salt and health.

a Argentina (Cañada de Gómez, Villa Gobernador Gálvez, and Rosario), Canada (Calgary), Chile (Santiago), Costa Rica (San José), and Ecuador (Quito).

tioned paying attention to health claims on packages. Almost $30 \%$ preferred to see information on the amount of both salt and sodium on nutrition labels rather than values on salt and sodium individually. More than $80 \%$ would like food labeling to indicate high, medium, and low levels of salt or sodium and would like to see a clear warning label on packages if foods are high in salt. Almost half the participants preferred food labeling to indicate salt or sodium per portion rather than per total amount per package and more than $70 \%$ would like food labeling to indicate salt (or sodium) as a percentage of the amount recommended to be eaten per person per day.

\section{DISCUSSION}

Through data collected in five sentinel countries in the Americas, this study was able to report important findings about consumers' attitudes, knowledge, and behavior related to salt intake and food labeling preferences. Almost 90\% of participants associated excessive intake of salt with the occurrence of adverse health conditions, more than $60 \%$ indicated trying to reduce their current intake of salt, and more than $30 \%$ believed reducing dietary salt to be of high importance. Meanwhile, three-quarters of participants $(74 \%)$ declared they did not know about the existence of a recommended maximum value of salt or sodium intake (ranging from $94 \%$ in Argentina to $46 \%$ in Canada) and only about half of them (47\%) indicated they knew the content of salt in food items. These results indicate that, while some knowledge related to excessive salt intake is already well disseminated, there remains a great need for more knowledge propagation.

This survey is the first one to analyze consumers' attitudes, knowledge, and behavior related to salt intake in developing countries. Similar studies have been conducted in developed countries such as Australia (21) and Canada (20, 22).

Although the results show that most participants were aware that salt and sodium consumption is an important health issue, the fact that only a minority recognize the existence of a recommended maximum level of sodium intake or believe they consume a high amount of salt and sodium is a reason for concern. This study did not estimate actual consumption of sodium; however, external evidence shows that current intake of sodium in American countries far exceeds recommended maximum levels of consumption $(8,9,11-13)$. This finding endorses the hypothesis that individuals are not effective at controlling their sodium intake, in part because they do not recognize that they personally consume too much sodium, even if they recognize that other people consume too much (17). This fact proves the need to reduce the salt content of processed foods and to implement additional interventions to help increase individuals' awareness of the content of salt in food items and thus of their salt intake. Participants in this study favored warning 
TABLE 4. Percentage of participants claiming to know the existence of a recommended maximum value of salt and sodium intake according to gender, age group, and education $(n=1992)$ in five sentinel countries of the Americas, ${ }^{a} 2010$

\begin{tabular}{lcccccc}
\hline & \multicolumn{5}{c}{ Percent of participants } \\
\cline { 2 - 7 } Variable & Total & Argentina & Canada & Chile & Costa Rica & Ecuador \\
\hline $\begin{array}{l}\text { Gender } \\
\text { Male }\end{array}$ & 22.0 & 3.0 & 43.5 & 17.6 & 37.2 & 9.0 \\
$\quad$ Female & 29.4 & 8.6 & 60.8 & 27.5 & 37.3 & 11.6 \\
Age group (years) & & & & & & \\
$\quad$ 18-24 & 31.8 & 8.9 & 55.2 & 22.4 & 26.4 & 0.0 \\
25-34 & 25.1 & 8.7 & 49.5 & 18.3 & 41.7 & 4.3 \\
35-44 & 24.3 & 5.6 & 60.9 & 24.3 & 37.9 & 10.7 \\
45-54 & 23.8 & 6.2 & 56.1 & 21.7 & 47.5 & 14.0 \\
55-64 & 25.3 & 3.7 & 42.3 & 42.1 & 55.2 & 18.2 \\
$\quad$ 65 & 24.6 & 3.3 & 58.1 & 50.0 & 20.0 & 8.3 \\
Education & & & & & & \\
$\quad$ None and primary & 14.8 & 2.1 & 46.7 & 31.0 & 24.3 & 4.3 \\
Secondary & 22.6 & 4.3 & 56.0 & 19.6 & 29.9 & 5.7 \\
$\quad$ Higher & 34.7 & 15.6 & 54.2 & 25.7 & 48.2 & 17.4 \\
Total & 26.2 & 6.3 & 54.1 & 22.8 & 37.3 & 10.4 \\
\end{tabular}

Source: question 10 from Appendix 1: Survey on knowledge, attitude and behavior toward dietary salt and health.

a Argentina (Cañada de Gómez, Villa Gobernador Gálvez, and Rosario), Canada (Calgary), Chile (Santiago), Costa Rica (San José), and Ecuador (Quito)

TABLE 5. Summary of responses concerning relationship between food labeling and salt and sodium consumption $(n=1992)$ in five sentinel countries of the Americas, ${ }^{a} 2010$

\begin{tabular}{|c|c|c|c|c|c|c|}
\hline \multirow[b]{2}{*}{ Statement } & \multicolumn{6}{|c|}{ Percent agreeing with statement } \\
\hline & Total & Argentina & Canada & Chile & Costa Rica & Ecuador \\
\hline $\begin{array}{l}\text { I always or often read nutrition labels } \\
\text { on food packages. }\end{array}$ & 34.9 & 28.0 & 58.1 & 32.8 & 24.7 & 30.7 \\
\hline $\begin{array}{l}\text { I always or often pay attention to } \\
\text { indications on packages like "no } \\
\text { added salt," "low in salt," "light," } \\
\text { and "free of trans fat." }\end{array}$ & 40.2 & 35.3 & 47.6 & 56.0 & 35.6 & 26.2 \\
\hline $\begin{array}{l}\text { I prefer to see information on the } \\
\text { amount of salt and sodium on } \\
\text { nutrition labels on food packages } \\
\text { rather than on any of them }\end{array}$ & & & & & & \\
\hline individually. & 28.2 & 31.0 & 31.3 & 46.3 & 14.9 & 17.4 \\
\hline $\begin{array}{l}\text { I would like labeling of food indicating } \\
\text { high, medium, and low levels of } \\
\text { salt or sodium. }\end{array}$ & 81.2 & 88.0 & 70.7 & 84.8 & 80.8 & 81.9 \\
\hline $\begin{array}{l}\text { I would like to see a clear warning } \\
\text { label on the package if foods are }\end{array}$ & & & & & & \\
\hline $\begin{array}{l}\text { high in salt or sodium. } \\
\text { I prefer labeling of food indicating salt } \\
\text { or sodium per portion rather than }\end{array}$ & 85.8 & 93.3 & 75.4 & 91.8 & 87.9 & 80.9 \\
\hline $\begin{array}{l}\text { per total amount per package. } \\
\text { I would like labeling of food indicating }\end{array}$ & 47.9 & 53.0 & 42.1 & 55.5 & 36.9 & 51.9 \\
\hline eaten per person per day. & 73.7 & 88.5 & 76.2 & 73.8 & 81.8 & 48.1 \\
\hline
\end{tabular}

Source: questions from Appendix 1: Survey on knowledge, attitude and behavior toward dietary salt and health.

a Argentina (Cañada de Gómez, Villa Gobernador Gálvez, and Rosario), Canada (Calgary), Chile (Santiago), Costa Rica (San José), and Ecuador (Quito).

labels on foods that clearly indicate high or low salt content as a mechanism to help them reduce their salt consumption.

More than half of participants stated that they tried to minimize their intake of dietary salt. The frequency of participants trying to reduce dietary salt intake was related to the capacity to recognize a high sodium intake as a potential health threat. The same situation was found in the number of individuals placing high importance on reducing their salt and sodium intake. This study reinforces the findings of previous studies demonstrating that consumers tend to be positively influenced by health communication aimed at educating them about the importance of reducing their salt intake (23). It is worth mentioning that the highest percentage of consumers aware of the risks associated with excessive consumption of salt was found in Canada, a country where extensive actions to improve populations' awareness and reduce salt consumption have been implemented for more than 5 years $(15,24)$.

The large proportion of consumers in this study who stated they did not know the difference between salt and sodium is also a matter of concern. Although most participants reported not knowing the difference between salt and sodium, an impressive proportion of those who reported knowing the difference failed to correctly identify what the difference was. On average, a correct answer was obtained for only 1 in 9 people in Costa Rica, going down to 1 in 45 in Ecuador (data not shown). This lack of basic nutrition knowledge could lead to misinterpretation of or inability to read nutrition labels on food packages (traditionally information is displayed as sodium content) (25). While half the participants in Canada reported they read nutrition labels always or often, only one-third of participants from the other countries stated this behavior. Still, it is known that these findings could actually overestimate real nutrition label use as they rely on self-reported information instead of more accurate measures (26, 27). These responses were validated by the small amount of participants reporting they knew the content of salt in food items. Raising consumers' awareness may increase their use of nutrition labels and thus the purchase of foods with a low sodium content. To be able to recognize dietary sources of sodium is an important step in reducing consumption at the individual level. This ability gains even more importance in countries where the majority of salt intake comes from processed food items, such as Canada (28) and Argentina (9).

Thus, changes in nutrition labels and food packages are likely to improve the ability of consumers to identify the sodium content of food items. Consumers in this study did not show a specific preference between salt or sodium data on nutrition labels. In fact, the largest share of participants wanted to have both salt and sodium mentioned. While almost $40 \%$ of participants reported already paying attention to health claims 
on food packages (such as "no added salt" or "low in salt"), the vast majority of them stated they would like to see clear and objective information on food packages (such as a clear warning when foods are high in salt or sodium). Similar results have been found in the United Kingdom $(29,30)$ with the traffic light labeling system, which is expanding to other European countries on a voluntary basis. In a study conducted in the United Kingdom with 2932 consumers, use of the traffic light labeling system favored consumers' understanding of nutritional information compared with traditional labeling, suggesting that this more explicit but simple labeling might transmit nutritional messages in a more effective way than traditional labeling (30).

Important limitations in the design of this study should be noted. First, the study used a convenience sample, and the recruitment of participants was limited to shopping malls or major commercial areas. Second, the samples have a different sociodemographic profile than the population of each city surveyed, specifically in relation to the larger presence of women and more highly educated individuals. As previous studies generally indicate a direct relationship between schooling and health awareness (31), there might be an overestimation of the positive findings (and an underestimation of the negative ones), meaning that the scenario in the general population of each city is probably worse than the one shown here. These limitations also imply that the findings from this study cannot be extrapolated to the entire population of each studied city (or country). Differences in the demographic characteristics of the participants in each country were also found, rendering direct comparisons between countries impossible. A study with a higher prevalence of highly educated individuals or younger individuals also tends to have a higher proportion of positive findings. Lastly, even though the questionnaire was pilot tested in each of the study sites, this study did not rely on a validated questionnaire.

In conclusion, the findings from this study indicate that additional effort is required to increase consumers' knowledge, mainly about the existence of a maximum limit for salt or sodium intake, and to improve their capacity to accurately monitor and reduce their personal salt consumption. In relation to food labeling, the results show that traditional labeling (information panel showing sodium content) is challenging to interpret and often is not used to guide consumers' decisions. Fewer than half of participants said they read nutritional information on food labels or paid attention to special claims on the package, pinpointing the need to improve awareness of these important information strategies. The high percentage of consumers desir- ing information on food labels indicating the amount of salt in the item or a clear warning label on the package of foods high in salt indicates that it might be necessary to develop a clearer labeling format. In the meantime, the high numbers of consumers aware of the need to reduce salt or sodium intake and of consumers trying to minimize their current salt intake are very positive findings and should be reinforced. Next phases include extending the survey to other countries in the Americas (e.g., Bolivia and Brazil) and replicating it in the same countries in order to explore the impact of PAHO's work on reducing salt intake.

Acknowledgments. The authors thank the PAHO Area of Health Surveillance and Disease Control and CIHR Canada Chair in Hypertension Prevention and Control for funding this survey as part of the project on noncommunicable diseases. The authors also thank Valeria Vaccaro of Unión de Usuarios y Consumidores, Filial Rosario; Cinthya Appelgren of Conadecus; Carolina Rodriguez of Fundación Bandera Ecológica; and Isabel Muñoz of Tribuna Ecuatoriana, representatives of the consumer organizations in Argentina, Chile, Costa Rica, and Ecuador, respectively, who coordinated the survey in their countries and provided the raw data. R.M.C. received a postdoctoral fellowship from the São Paulo State Research Foundation.

\section{REFERENCES}

1. World Health Organization. Reducing salt intake in populations: report of a WHO forum and technical meeting, 5-7 October 2006, Paris, France. Geneva: WHO; 2007.

2. He FJ, MacGregor GA. A comprehensive review on salt and health and current experience of worldwide salt reduction programmes. J Hum Hypertens. 2009;23: 363-84.

3. Cappuccio FP, Kalaitzidis R, Duneclift S, Eastwood JB. Unravelling the links between calcium excretion, salt intake, hypertension, kidney stones and bone metabolism. J Nephrol. 2000;13:169-77.

4. Tsugane S. Salt, salted food intake, and risk of gastric cancer: epidemiologic evidence. Cancer Sci. 2005;96(1):1-6.

5. Woo J, Kwok T, Leung J, Tang N. Dietary intake, blood pressure and osteoporosis. J Hum Hypertens. 2009;23:451-5.

6. He FJ, Marrero NM, MacGregor GA. Salt intake is related to soft drink consumption in children and adolescents: a link to obesity? Hypertension. 2008;628-34.

7. Ezzati M, Lopez AD, Rodgers A, Hoorn SV, Murray CJL, Comparative Risk Assessment Collaborating Group. Selected major risk factors and global and regional burden of disease. Lancet. 2002. Available from: http://image. thelancet.com/extras/02art9066web.pdf Accessed 19 November 2011.

8. Brown IJ, Tzoulaki I, Candeias V, Elliott P. Salt intakes around the world: implications for public health. Int J Epidemiol. 2009;38:791813.

9. Ministerio de Salud de Argentina. Encuesta Nacional de Nutrición y Salud 2004-2005. Buenos Aires: Ministerio de Salud de Argentina; 2008

10. Sarno F, Claro RM, Levy RB, Bandoni DH, Ferreira SRG, Monteiro CA. Estimativa de consumo de sódio pela população brasileira, 2002-2003. Rev Saude Pública. 2009;43(2): 219-25.
11. Garriguet D. Sodium consumption at all ages. Health Rep. 2007;18(2):47-52.

12. Legetic B, Campbell N. Reducing salt intake in the Americas: Pan American Health Organization actions. J Health Commun. 2011;16(Suppl 2):37-48.

13. Institute of Medicine. Strategies to reduce sodium intake in the United States. Washington, D.C.: IOM; 2010.

14. Smith-Spangler CM, Juusola JL, Enns EA, Owens DK, Garber AM. Population strategies to decrease sodium intake and the burden of cardiovascular disease: cost-effectiveness analysis. Ann Intern Med. 2010;152:481-7.

15. Campbell NRC, Willis KJ, L'Abbe M, Strang $\mathrm{R}$, Young E. Canadian initiatives to prevent hypertension by reducing dietary sodium. Nutrients. 2011;3:756-64.

16. Pan American Health Organization. First meeting of expert group on CVD prevention through dietary salt reduction. Washington, D.C.: PAHO; 2009. Available 
from: http://new.paho.org/hq/index. php?option $=$ com_content\&task $=$ view\&id $=2024 \&$ Itemid $=1963$ Accessed 19 November 2011.

17. World Health Organization. Sample size determination in health studies. A practical manual. Geneva: WHO; 1991.

18. Australian Division of World Action on Salt and Health. 2007 survey of Australian consumer awareness and practices relating to salt. Sydney: AWASH; 2007. Available from: http://www.awash.org.au/documents / AWASH_ConsumerSurveyReport_2007_05_15.pdf Accessed 17 November 2011.

19. Consensus Action on Salt and Health. Salt survey in adults. London: CASH; 2003. Available from: http://www.actiononsalt. org.uk/less/what/adults/index.html Accessed 12 November 2011.

20. Public Health Agency of Canada. Canadians' and health care professionals' views on sodium. Commissioned public opinion research to inform the working group about Canadians' current awareness about sodium. Ottawa: Public Health Agency of Canada; 2009. Available from: http:// epe.lac-bac.gc.ca/100/200/301/pwgsc- tpsgc/por-ef/public_health_agency_canada/2009/117-08/report.pdf Accessed 8 October 2012.

21. Grimes CA, Riddell LJ, Nowson CA. Consumer knowledge and attitudes to salt intake and labelled salt information. Appetite. 2009;53:189-94.

22. Papadakis S, Pipe AL, Moroz IA, Reid RD, Blanchard CM, Cote DF, et al. Knowledge, attitudes and behaviours related to dietary sodium among 35- to 50-year-old Ontario residents. Can J Cardiol. 2010;26(5):e164-9.

23. Snyder LB. Health communication campaigns and their impact on behavior. J Nutr Educ Behav. 2007;39:S32-40.

24. Stankus V, Hemmmelgarn B, Campbell NRC, Chen G, McAlister FA, Tsuyuki RT. Reducing costs and improving hypertension management. Can J Clin Pharmacol. 2009;16(1):e1515.

25. Drichoutis AC, Lazaridis P. Nutrition knowledge and consumer use of nutritional food labels. Eur Rev Agric Econ. 2005;32(1):93-118.

26. Jones G, Richardson M. An objective examination of consumer perception of nutrition information based on healthiness ratings and eye movements. Public Health Nutr. 2007;10(3):238-44.
27. Higginson CS, Rayner MF, Draper S, Kirk TR. The nutrition label-which information is looked at? Nutr Food Sci. 2002;32(3):92-9.

28. Fisher PWF, Vigneault M, Huang R, Arvaniti K, Roach P. Sodium food sources in the Canadian diet. Appl Physiol Nutr Metab. 2009;34(5):884-92.

29. Kelly B, Hughes C, Chapman K, Louie J, Dixon H, King L. Front-of-pack food labelling: traffic light labelling gets the green light. Sydney: Cancer Council; 2008.

30. Faculty of Public Health. Traffic-light food labeling: a position statement. London: Faculty of Public Health; 2008.

31. Yen $\mathrm{IH}$, Moss N. Unbundling education: a critical discussion of what education confers and how it lowers risk for disease and death. In: Adler NE, Marmot M, McEwen B, Stewart $\mathrm{J}$, eds. Socioeconomic status and health in industrialized nations: social, psychological, and biological pathways. New York: New York Academy of Sciences; 1999. Pp. 350-1.

Manuscript received on 13 March 2012. Revised version accepted for publication on 25 October 2012.

\section{APPENDIX 1. Survey on knowledge, attitude and behavior toward dietary salt and health}
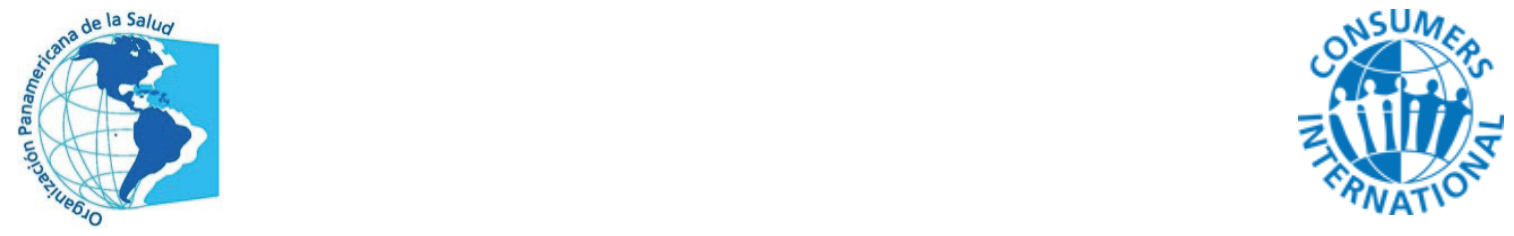

\section{QUESTIONNAIRE}

\begin{tabular}{|c|c|c|c|c|c|}
\hline No: & \multicolumn{2}{|l|}{ Date: } & \multicolumn{3}{|l|}{ Interviewer: } \\
\hline \multicolumn{6}{|l|}{ Age } \\
\hline \multicolumn{2}{|l|}{ Sex } & \multicolumn{2}{|c|}{ female } & \multicolumn{2}{|c|}{ male } \\
\hline Children under 16 and living at home & yes & no & no answer & & \\
\hline Highest education level & none & primary & secondary & higher & no answer \\
\hline
\end{tabular}

Attitude statements

\begin{tabular}{|c|c|c|c|c|}
\hline I try to eat a healthy diet & agree & disagree & don't know & no answer \\
\hline Eating a diet high in salt can cause serious health problems & agree & disagree & don't know & no answer \\
\hline I try to minimize the amount of fat I eat & agree & disagree & don't know & no answer \\
\hline My health is generally good & agree & disagree & don't know & no answer \\
\hline I try to minimize the amount of salt I consume & agree & disagree & don't know & no answer \\
\hline I know in general how much salt food contains & agree & disagree & don't know & no answer \\
\hline There is sufficient nutritional information on labels of food and drinks & agree & disagree & don't know & no answer \\
\hline
\end{tabular}

1. How often do you add salt to food at the table?

\begin{tabular}{|c|c|c|c|c|c|}
\hline never & rarely & sometimes & often & always & don't know \\
\hline \multicolumn{6}{|c|}{ 2. In the food you eat at home salt is added in cooking } \\
\hline never & rarely & sometimes & often & always & don't know \\
\hline
\end{tabular}

3. How much salt do you think you consume?

\begin{tabular}{|c|c|c|c|c|}
\hline too much & right amount & too little & don't know & no answer \\
\hline
\end{tabular}


4. What sort of health problem do you think can be caused by a high salt diet? (do not read aloud + tick all that apply)

\begin{tabular}{|l|l|}
\hline a) high blood pressure & b) osteoporosis \\
\hline c) stomach cancer & d) kidney stones \\
\hline e) heart attack/heart failure & f) stroke \\
\hline g) asthma & h) other (specify): \\
\hline i) none & \\
\hline j) don't know & k) no answer \\
\hline
\end{tabular}

5. Do you suffer from or have you suffered from: ?

\begin{tabular}{|l|c|c|c|c|}
\hline High blood pressure & yes & no & don't know & no answer \\
\hline Heart attack & yes & no & don't know & no answer \\
\hline Stroke & yes & no & don't know & no answer \\
\hline Kidney stones & yes & no & don't know & no answer \\
\hline Asthma & yes & no & don't know & no answer \\
\hline Osteoporosis & yes & no & no answer \\
\hline Stomach cancer & yes & no & don't know & no answer \\
\hline
\end{tabular}

6. Limiting the amount of salt/sodium I eat is important to me.

6. Limiting the amount of salt/sodium I eat is important to me.
\begin{tabular}{|c|c|c|c|c|}
\hline not at all & somewhat & very & don't know & no answer \\
\hline
\end{tabular}

\section{What, if anything, do you do to control your salt or sodium intake?}

\section{Do you know if there is a recommended amount for salt/sodium to be eaten per person per day?}

\begin{tabular}{|c|c|c|c|}
\hline yes & no & don't know & no answer \\
\hline
\end{tabular}

9. If yes, please indicate the amount?

10. Do you know the difference between salt and sodium?

\begin{tabular}{|c|r|r|r|}
\hline yes & no & don't know & no answer \\
\hline
\end{tabular}

11. If yes, please indicate the difference?

12. Do you pay attention to indications on packages like "no added salt", "low in salt", "light", "free of trans fat"?

\begin{tabular}{|c|c|c|c|c|c|c|}
\hline always & often & sometimes & rarely & never & don't know & no answer \\
\hline
\end{tabular}

13. How often do you read nutrition labels on food packages?

\begin{tabular}{|c|c|c|c|c|c|c|}
\hline always & often & sometimes & rarely & never & don't know & no answer \\
\hline
\end{tabular}

14. What do you prefer on nutrition labels on food packages?

\begin{tabular}{|c|c|c|c|c|}
\hline salt & sodium & salt and sodium & don't know & no answer \\
\hline
\end{tabular}

15. Why?

16. Would you like labelling of food indicating high/medium/low levels of salt or sodium?

\begin{tabular}{|c|c|c|c|}
\hline yes & no & don't know & no answer \\
\hline
\end{tabular}


17. Would you like to see a clear warning label on the package if foods are high in salt?

\begin{tabular}{|c|c|c|c|}
\hline yes & no & don't know & no answer \\
\hline
\end{tabular}

18. Would you like labelling of food indicating the amount of salt or sodium in grams or milligrams?

\begin{tabular}{|c|c|c|c|}
\hline yes & no & don't know & no answer \\
\hline
\end{tabular}

19. Would you like labelling of food indicating salt or sodium as a percentage of the amount recommended to be eaten per person per day?

\begin{tabular}{|c|c|c|c|}
\hline yes & no & don't know & no answer \\
\hline
\end{tabular}

20. Do you prefer labelling of food indicating salt or sodium per portion or the total amount per package?

\begin{tabular}{|c|c|c|c|c|}
\hline per portion & per $100 \mathrm{gr}$ & total per package & don't know & no answer \\
\hline
\end{tabular}

\section{Comments:}

RESUMEN Objetivo. Describir las actitudes, los conocimientos y el comportamiento individuales con respecto al consumo de sal, sus fuentes alimentarias, y las prácticas actuales de etiquetado de alimentos en relación con su contenido en sal y sodio en cinco países

Actitudes, conocimientos y comportamiento de los consumidores en relación con el consumo de sal en países centinelas de la Región de las Américas centinelas de la Región de las Américas.

Métodos. De septiembre del 2010 a febrero del 2011, se obtuvo una muestra de conveniencia de 1992 adultos (de 18 años de edad o mayores) de Argentina, Canadá, Chile, Costa Rica y Ecuador (aproximadamente 400 de cada país). Se llevó a cabo la recopilación de datos en centros o áreas comerciales importantes mediante un cuestionario de 33 preguntas. Se presentan los cálculos descriptivos correspondientes a la muestra total y estratificados por países y según las características sociodemográficas de la población estudiada.

Resultados. Casi $90 \%$ de los participantes asociaron la ingesta excesiva de sal con la aparición de trastornos de salud, más de $60 \%$ señalaron que estaban tratando de reducir su ingesta de sal actual, y más de $30 \%$ creían que la reducción de la sal alimentaria era de gran importancia. Solo $26 \%$ de los participantes manifestaron que conocían la existencia de un valor máximo recomendado de ingesta de sal o sodio, y $47 \%$ de estos afirmaron que conocían el contenido de sal de los productos alimenticios. Más de $80 \%$ de los participantes dijeron que les gustaría que el etiquetado de los alimentos indicara si los niveles de sal o sodio eran altos, medios o bajos, y desearían que en los paquetes de los alimentos con alto contenido de sal apareciera una etiqueta de advertencia clara.

Conclusiones. Se requieren nuevas iniciativas para incrementar los conocimientos de los consumidores acerca de la existencia de un límite máximo de ingesta y mejorar su capacidad para vigilar estrictamente y reducir el consumo de sal.

Palabras clave Sodio; actitud; conocimiento; conducta; organizaciones del consumidor; Américas. 